\title{
Prevalence of Rubber Dam Usage Among Dental Practitioners and Final Year Students in Tirgu Mures: A Questionnaire Survey
}

\author{
K.-Ivácson A. Csinszka ${ }^{1 *}$, Monea Monica1 ${ }^{1}$ Pop Mihai ${ }^{1}$, Albu-Stan Aurita², Borda Angela ${ }^{3}$ \\ ${ }^{1}$ Discipline of Odontology and Oral Pathology, Faculty of Dentistry, University of Medicine and Pharmacy Tirgu Mures \\ 2 PHD student, University of Medicine and Pharmacy Tirgu Mures \\ 3 Discipline of Histology, Faculty of Medicine, University of Medicine and Pharmacy Tirgu Mures Mures
}

The purpose of this study was to determine the prevalence of rubber dam usage among endodontists, other specialized practitioners, general practitioners and undergraduate final year students in Tirgu-Mures, Romania.

Material and method: A questionnaire was distributed among 250 subjects. Final year students and dentists were surveyed in relation to their prevalence of rubber dam usage.

Results: Overall response rate was 72,4 . While $84,07 \%$ of the subjects knew about the advantages, only $49,72 \%$ used it during their practice, mostly endodontist (90\%) and other specialized practitioners (53,84\%). The use of this system on pediatric patients was lower compared to adult patients. The frequency of the rubber dam usage during endodontic treatment was higher $(71,11 \%)$ compared to dental restorations $(35,55 \%)$, and $84,49 \%$ of the subjects were are willing to gain further knowledge about this system.

Conclusions: The results were similar to other reports originally from Eastern-European countries. The low percentage of the rubber dam usage presents quality issues, safety and medico-legal concerns for both the patient and the dentist. Greater emphasis should be placed on the advantages of rubber dam. Perception of final year dental students needs to be improved and continuing dental education for practitioners should be necessary to update their knowledge.

Keywords: questionnaires, rubber dam, isolation

Received: 09 December 2014 / Accepted: 04 June 2015

\section{Introduction}

Isolation of the operative field during dental interventions is imperative or even obligatory in some cases, like root canal treatment. Absolute isolation of the area can be obtained only by using the rubber dam [1].

The rubber dam was initially discovered in 1864 in New York, USA by Sanford Christie Barnum. At that time keeping in place the dam was problematic, but a few years later, in 1882 S. S. White improved the system making it similar to the rubber dam used nowadays. After 150 years it is incredible that there are dentists who still ignore the advantages and are not convinced by the usefulness of this system [2].

This system presents a few contraindications. In rare cases patients could present allergy to the chemical constituents of the rubber dam. This problem is already solved since latex-free rubber dams are on sale, too. When placed, some patients could present claustrophobic symptoms. Dental practitioners -who do not use this system- consider that placing the rubber dam is a time consuming procedure. Cragg said about this false opinion that "it takes more time to convince the doctor to use it, than eventually using it" (the rubber dam) [3].
The rubber dams advantages should make its' usage compulsory in some stages of dental treatment $[4,5]$. The rubber dam insures a clean surgical field. By retracting the soft tissues, it provides the protection of the tissues and offers a better visibility for the doctor during the treatment. Another important advantage of this system is the protection from infection for dentists and dental assistants. It is an indispensable element which protects the patient from ingestion and aspiration of small instruments and irrigating solutions [6-8]. So this systems use has even a medicolegal point of view. The rubber dam is comfortable for the patient because no hands, instruments and irrigation solutions enter in the mouth and allows swallowing, coughing and even yawning [9-12].

Taking these in consideration, it can be admitted that the use of the rubber dam should be compulsory not only among specialist but among general practitioners, too. The primary education is also important, students should be guided to use this system [13-15].

The purpose of this study was to determine the prevalence of rubber dam usage among endodontists, other specialized practitioners, general practitioners and undergraduate final year students in Tirgu-Mures, Romania. 


\section{Materials and methods}

A 15 point questionnaire was distributed among final year students and dentists working at our dental college and in private practices in Tirgu-Mures, Romania.

The subjects participating in our survey were divided into 5 groups:

- Group 1.- Endodontists

- Group 2.- Other specialized practitioners

- Group 3.- General practitioners with less than 10 years experience

- Group 4.- General practitioners with more than 10 years experience

- Group 5.- Final year students

The questionnaires were distributed among the final year students in lecture halls, the doctors were approached personally. Some of the doctors were contacted on the phone or by e-mail.

In each group the completed questionnaires were divided into 2 other groups:

1. Doctors/students who use the rubber dam in their practice

2. Doctors/students who do not use the rubber dam in their practice

The completed questionnaires were collected and distributed into the 5 groups. Statistics were performed with GraphPad Prism and Microsoft Excel sheets have been used to generate graphics. The statistics were analysed by Chi square/ Fishers Exact tests to find the significance of the parameters between the groups. The statistical significance was set at a $p$ value of 0.005 .

\section{Results}

Two hundred and fifty questionnaires were distributed among dentists and students. Overall response rate was $72,4 \%$. 181 persons completed the questionnaire, as follows: 20 endodontists, 52 other specialists, 36 general practitioners with less than 10 years experience, 22 general practitioners with more than 10 years experience and 51 final year students.

The results showed that:

- $39.2 \%$ of the persons gained information about this system in dental school and $9.89 \%$ had no information about this system.

- $49.73 \%$ of the answering persons used the rubber dam during their practice. $83.32 \%$ use this system on pediatric patients rarely or frequently, while on adult patients we found a percentage of $100 \%$.

- $26.66 \%$ of the total persons do not use the rubber dam during conservative treatment procedures (dental fillings). During endodontic procedures the rubber dam isolation is used frequently in $62.23 \%$ of the cases.

- $84.73 \%$ of the persons who completed the questionnaire would like to gain further knowledge about the rubber dam.
Small crowns and teeth with no retentivity were considered the most important things what harden the rubber dams application.

Among those who do not use this system the main cause was that it is considered to be a time consuming procedure and discomfortable for the patient.

Table I. General questions about the rubber dam

\begin{tabular}{|c|c|c|c|}
\hline $\begin{array}{l}\text { Where have you heard about } \\
\text { the rubber dam isolation? }\end{array}$ & $\begin{array}{l}\text { Users of the } \\
\text { dam }\end{array}$ & Not users & Total \\
\hline At the university & $33(36.67 \%)$ & $38(41.75 \%)$ & $71(39.21 \%)$ \\
\hline $\begin{array}{l}\text { On postuniversitary courses, } \\
\text { conferences }\end{array}$ & 30 (33.33 \%) & 27 (29.67 \%) & $57(31.50 \%)$ \\
\hline $\begin{array}{l}\text { Other source (friends, } \\
\text { internet) }\end{array}$ & $27(30 \%)$ & 9 (9.90\%) & $36(19.88 \%)$ \\
\hline I have not heard about it & 0 & $17(18.68 \%)$ & 17 (9.40 \%) \\
\hline $\begin{array}{l}\text { Do you know the rubber } \\
\text { dams advantages? }\end{array}$ & $\begin{array}{l}\text { Users of the } \\
\text { dam }\end{array}$ & Not users & Total \\
\hline Totally & 65 (72.22 \%) & $29(31.86 \%)$ & $94(52.04 \%)$ \\
\hline Partly & $25(27.77 \%)$ & $49(53.85 \%)$ & $74(40.81 \%)$ \\
\hline No & 0 & $13(14.28 \%)$ & $13(7.14 \%)$ \\
\hline
\end{tabular}

USE OF THE RUBBER DAM

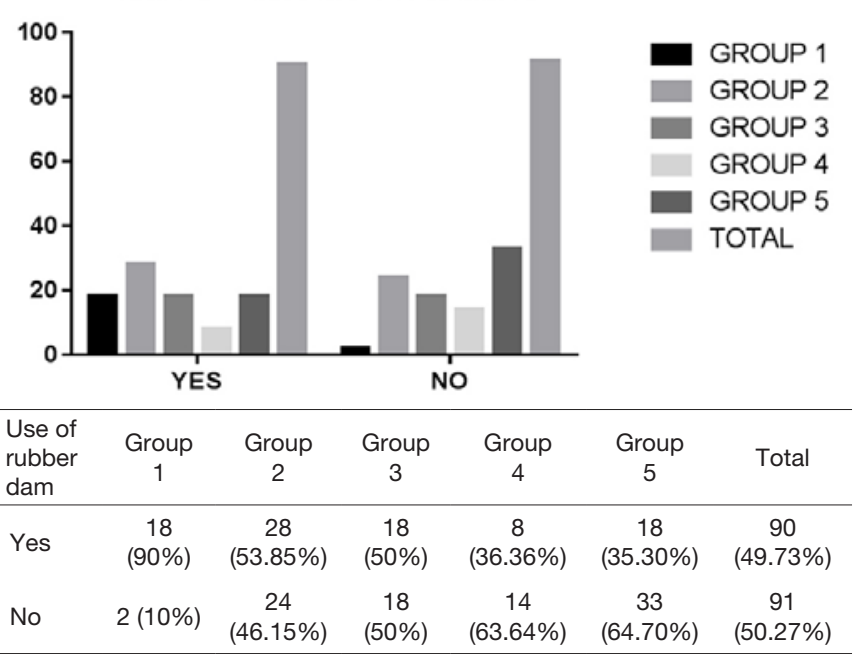

$\mathrm{p}=0.0018$ (statistically significant)

Fig. 1. Distribution of the rubber dam usage among different groups

\section{WHAT MAKES THE RUBBER DAM DIFFICULT} TO USE ?

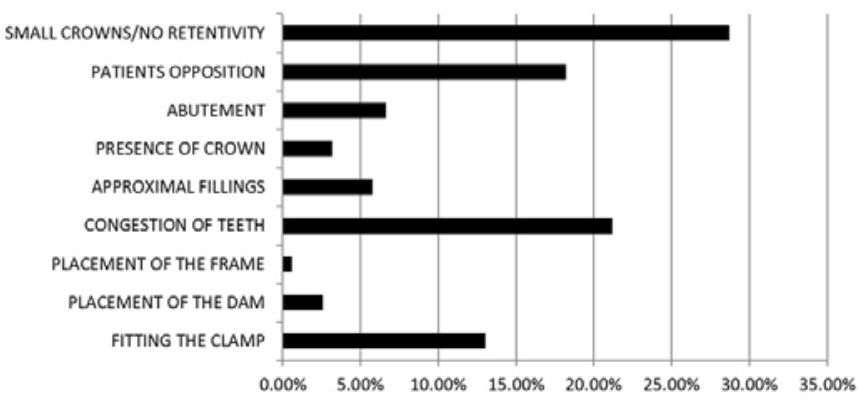

Fig. 2. Information about the difficulty in use of the rubber dam 
Table II. Questions about the rubber dam usage

\begin{tabular}{|c|c|c|c|c|c|c|}
\hline & Group 1 & Group 2 & Group 3 & Group 4 & Group 5 & Total \\
\hline \multicolumn{7}{|l|}{ Usage on pediatric patients } \\
\hline Not using & 0 & $6(21.24 \%)$ & $4(22.22 \%)$ & 0 & $5(27.77 \%)$ & $15(16.66 \%)$ \\
\hline Rarely & $10(55.55 \%)$ & $8(28.57 \%)$ & $4(22.22 \%)$ & $8(100 \%)$ & $7(38.88 \%)$ & $43(47.77 \%)$ \\
\hline Frequently & $8(44.44 \%)$ & $14(50 \%)$ & $10(55.55 \%)$ & 0 & $6(33.33 \%)$ & $32(35.55 \%)$ \\
\hline \multicolumn{7}{|l|}{ Usage on adult patients $(p=0.0001)$} \\
\hline Rarely & 0 & $12(42.85 \%)$ & $8(44.44 \%)$ & $8(100 \%)$ & $6(33.33 \%)$ & $34(37.77 \%)$ \\
\hline Frequently & $18(100 \%)$ & $16(57.14 \%)$ & $10(55.55 \%)$ & 0 & $12(66.66 \%)$ & $56(62.23 \%)$ \\
\hline \multicolumn{7}{|c|}{ Usage during dental fillings $(p=0.5114)$} \\
\hline Not using & $4(22.22 \%)$ & $6(21.42 \%)$ & $4(22.22 \%)$ & $2(25 \%)$ & $8(44.44 \%)$ & $24(26.66 \%)$ \\
\hline Rarely & $14(77.77 \%)$ & $16(57.14 \%)$ & $10(55.55 \%)$ & $4(50 \%)$ & $8(44.44 \%)$ & $52(57.77 \%)$ \\
\hline Frequently & 0 & $6(21.42 \%)$ & $4(22.22 \%)$ & $2(25 \%)$ & $2(11.11 \%)$ & $14(15.55 \%)$ \\
\hline \multicolumn{7}{|c|}{ Usage during endodontic treatment $(p=0.0011)$} \\
\hline Rarely & 0 & $6(21.42 \%)$ & $12(66.66 \%)$ & $4(50 \%)$ & $4(22.22 \%)$ & $26(28.88 \%)$ \\
\hline Frequently & $18(100 \%)$ & $22(78.57 \%)$ & $6(33.33 \%)$ & $4(50 \%)$ & $14(77.77 \%)$ & $64(71.11 \%)$ \\
\hline \multicolumn{7}{|c|}{ In which stage of the RCT do you use it? } \\
\hline After anesthesia & $10(55.55 \%)$ & $18(64.28 \%)$ & $12(66.66 \%)$ & $4(50 \%)$ & $13(72.22 \%)$ & $57(63.33 \%)$ \\
\hline After access cavity preparation & $8(44.44 \%)$ & $8(28.57 \%)$ & $2(11.11 \%)$ & $4(50 \%)$ & $1(5.55 \%)$ & $23(25.55 \%)$ \\
\hline Other stages & 0 & $2(7.14 \%)$ & $4(22.22 \%)$ & 0 & $4(22.22 \%)$ & $10(11.11 \%)$ \\
\hline \multicolumn{7}{|c|}{ If there is a massive crown distruction $(p=0.1585)$} \\
\hline $\begin{array}{l}\text { I prefer crown restoration and the } \\
\text { rubber dam isolation }\end{array}$ & $18(100 \%)$ & $22(78.57 \%)$ & $16(88.88 \%)$ & $6(75 \%)$ & $12(66.66 \%)$ & $74(82.22 \%)$ \\
\hline I do not use the rubber dam & 0 & $6(21.42 \%)$ & $2(11.11 \%)$ & $2(25 \%)$ & $6(33.33 \%)$ & $16(17.77 \%)$ \\
\hline \multicolumn{7}{|c|}{ On which group of the teeth do you use it? } \\
\hline Frontals & 0 & $1(3.57 \%)$ & 0 & 0 & $1(5.55 \%)$ & $2(1.10 \%)$ \\
\hline Premolars & 0 & $1(3.57 \%)$ & 0 & 0 & 2 (11.11\%) & $3(1.65 \%)$ \\
\hline Molars & 0 & 2 (7.14 \%) & 0 & 0 & $4(22.22 \%)$ & $6(3.13 \%)$ \\
\hline All groups & 100 (100\%) & $24(85.71 \%)$ & $18(100 \%)$ & $8(100 \%)$ & $11(61.11 \%)$ & $161(88.95 \%)$ \\
\hline
\end{tabular}

\section{WHY DON'T YOU USE THE RUBBER DAM?}

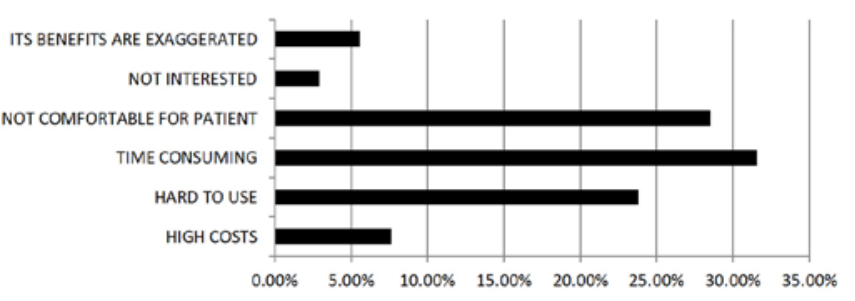

Fig. 3. Opinion of doctors/students who do not use the rubber dam

\section{Discussion}

Earlier survey findings suggest that use of rubber dam is associated with certain dental specialization, age and procedure characteristics [16-18], correlation also observed in our study.

The rubber dam isolation was used in the highest percentage among endodontists. This suggests that these specialists realize this systems importance and consider the rubber dams use mandatory especially during root canal treatment to increase the success of the treatment and prevent accidents.

Unfortunately the final year students' interest in using the rubber dam was low. We think that probably students are insufficiently motivated during practical stages to use this system.

Among general practitioners and other specialized practitioners almost half of the doctors used the rubber dam.
This is reassuring but through further trainings and courses this percentage could probably get even higher since the young doctors are more ambitious to improve the quality of their treatments.

The general practitioners with more than 10 years experience use the rubber dam in a low percentage. Among those who use this system unfortunately it is used only rarely.

Among the doctors and students who do not use the isolation with rubber dam almost $20 \%$ of the persons do not have information of this system. The main cause of not using the rubber dam was that the asked persons consider it a time consuming procedure and they assume that it causes discomfort for the patient. These answers are similar to other reports, [14] although other studies that actually surveyed patients have found that patients acceptance is high when asked about the rubber dam [19,20].

To the question if they want to get further knowledge about the rubber dam a high percentage of the asked persons responded positively. It is joyful that doctors and students are interested in obtaining further information about this system.

One limitation of this study could be that we restricted the questionnaire only to rubber dam isolation because this is by far the most accepted and effective method to perform a dental treatment by allowing better isolation, visibility and protection for both the doctor and the patient [21,22]. 


\section{Conclusion}

The low percentage of the rubber dam usage presents quality issues, safety and medico-legal concerns for both the patient and the dentist.

Greater emphasis should be placed on the advantages of rubber dam.

Perception of final year dental students needs to be improved and continuing dental education for practitioners should be necessary to update their knowledge.

\section{References}

1. Cochran MA, Miller $\mathrm{CH}$, Sheldrake MA The efficacy of rubber dam as a barrier to the spread of microorganisms during dental treatment. J Am Dent Assoc.1989;119:141-145.

2. Castelucci. Endodontics. Tooth Isolation: the Rubber Dam, chapter 10. 226-243.

3. Shashirekha J, Asim Bikash, Pankaj Kumar. Panda Prevalence of Rubber Dam Usage during Endodontic Procedure: A Questionnaire Survey. Journal of Clinical and Diagnostic Research. 2014 Jun.;Vol.8:ZC01ZCO3.

4. Cohen S. Endodontics and litigation: an American perspective. Int Dent J. 1989;39:13.

5. Cohen S. Schwartz.S. Endodontic complications and the law. J Endod. 1987;13:191-197.

6. Lambrianidis T, Beltes P. Accidental Swallowing of endodontic instruments. Endod Dent Traumatol. 1996;12:301-304.

7. The Dentist Insurance company, California Dental Association. Rubber dam it. Liability lifeline. 2004;80:1-7.

8. Goultschin J, Heling B. Accidental swallowing of an endodontic instrument. Oral Surg Oral Med Oral Pathol Oral Radiol Endod.
1971;32:621-622.

9. Ahmad IA. Rubber dam usage for endodontic treatment: a review. Int Endod J. 2009; 42:963-972.

10. Guideline on pulp therapy for primary and young permanent teeth. Pediatr Dent. 2008-2009;30:170-174.

11. Undergraduate curriculum guidelines for endodontology. European Society of Endodontology. Int Endod J. 2001;34:574-580.

12. Quality guidelines for endodontic treatment: consensus report of the European Society of Endodontology. Int Endod J. 2006;39:921-930.

13. Anabtawi, GH. Gilbert et al. and The DPBRN Collaborative Group. Rubber dam use during root canal treatment: findings from The Dental Practice-Based Research Network. J Am Dent Assoc. 2013 February; 144:179-186.

14. Jale Tanalp, Müzeyyen Kayata et al. Evaluation of Senior Dental Students' General Attitude towards the Use of Rubber Dam: A Survey among Two Dental Schools. The Scientific World Journal Volume. 2014;:Article ID 290101:7 pages.

15. Gregg HG, Mark SL, Daniel JP, Craig WA, Valeria VG. Rubber dam use during routine operative dentistry procedures: findings from the dental PBRN. Oper Dent. 2010;35:491-499.

16. M. Kapitán, Zdeňka Šustová. The Use of Rubber Dam among Czech Dental Practitioners. ACTA MEDICA (Hradec Králové). 2011;54:144148.

17. Marshall K, Page J. The use of rubber dam in the UK: A survey. Br Dent J. 1990;169:286-291.

18. Gergely EJ., Desmond Greer, Walker Award. Rubber dam acceptance. Br Dent J. 1989;167:249-252.

19. Stewardson DA, McHugh ES. Patients' attitudes to rubber dam. Int Endod J. 2002;35:812-819.

20. Summitt JB. Field Isolation. In: Summitt JB, Robbins JW, Hilton TJ, Schwarts RS, (eds.) Fundamentals of Operative Dentistry - A Contemporary Approach. 3. Chapter 7. Quintessence; Chicago: 2006;156-157.

21. Small BW. Rubber dam - the easy way. Gen Dent. 1999;47:30-33. 